\section{DENSITY OF HEAVY WATER}

BY Prof. TSING-LIEN CHANG

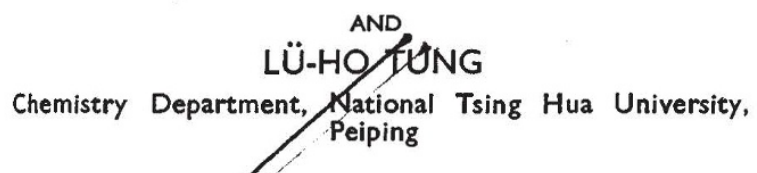

THE density of heavy water was accurately determine 6 by Stokland, Ronaess and Tronstad ${ }^{1}$ in the temperature range $10-27^{\circ}$. Measurements were extended to $50^{\circ}$ by Chang and Chien ${ }^{2}$, and later by Wirtz ${ }^{3}$. Recently, we have further extended the megsurement up to the boiling point of heavy water.

16-ml. quartz pycnometer consisting of a bulb with a short stem of $0.5-\mathrm{mm}$. calibre and a groundjoint cap was used. A thermostat kept the temperature constant within $0.01^{\circ}$. Special precautions were taken regarding the pycnometry, thermometry, purification of water, avoidance of contact with atmospheric moisture, reduction of the weighings to vacuum, and volume correction for the thermal expansion of vitreous quartz. In order to make sure of the accuracy of our measurements, we have determined the density of ordinary water between $50^{\circ}$ and $100^{\circ}$ and found that the results agree with Thiessen's data ${ }^{4}$ within three units in the fifth decimal place.

Two ampoules of heavy water of different concentrations supplied by Norsk Hydro-Elektrisk Kvaelstof A/S were distilled under vacuum direct into the pycnometer. The mole percentage of $\mathrm{D}_{2} \mathrm{O}$ was calculated ${ }^{5}$ from its density ratio $d_{25}^{25}$ in compar. ison with ordinary water at $25^{\circ}$. The Norwegian heavy water is known ${ }^{6}$ to contain 0.32 weight per cent $\mathrm{D}_{2} \mathrm{O}^{18}$. Three series of measurements were carried out on samples containing 99.71-99.77 mol. per cent $\mathrm{D}_{2} \mathrm{O}$ at intervals of $5^{\circ}$ between $25^{\circ}$ and $100^{\circ}$ with special attention to the temperature range above $50^{\circ}$. The density ratio $d_{25}^{25}$ of the sample was determined before and after each series of measurements.

From-the density values so obtained are subtracted those of ordinary water at the corresponding temperatures. The difference of density between heavy water and ordinary water is obtained by linear extrapolation. In the extrapolation to 100 per cent $\mathrm{D}_{2} \mathrm{O}$ with normal isotopic composition of oxygen, the excess of the oxygen-18 water is included in the $\mathrm{D}_{2} \mathrm{O}$ content. The possible error so introduced will not affect the fifth decimal place of the density value.

The density differences at various temperatures were smoothed by the graphical method. The mean deviation of the measured values from those of the smoothed curve is $0.00002 \mathrm{gm}$. $/ \mathrm{ml}$. Using Swift's value $^{5}$ for $5^{\circ}$ and Tronstad's values' between $10^{\circ}$ and $25^{\circ}$, we have prepared the accompanying table for the density of heavy water $\left(d_{\mathrm{D}_{3}}\right)$ in the liquid state, covering the complete temperature range between its freezing and boiling point. Considering the errors from different sources, we believe that our density values are accurate to $0.00005 \mathrm{gm} . / \mathrm{ml}$. The density of ordinary water $\left(d_{\mathrm{H}_{2} \mathrm{O}}\right)$ is also given for comparison, together with the density ratio of heavy and ordinary water. This ratio has also a tendency to pass over a maximum as predicted by Chang and Chien. The temperature for such a maximum seems to lie not far above the boiling point.

The density values in the temperature range between $30^{\circ}$ and $50^{\circ}$ formerly determined in this

\begin{tabular}{|c|c|c|c|c|}
\hline $\begin{array}{l}\text { Tempera- } \\
\text { ture }{ }^{\circ} \mathrm{C} \text {. }\end{array}$ & $\begin{array}{c}d \mathrm{H}_{2} \mathrm{O} \\
\mathrm{gm} . / \mathrm{ml} .\end{array}$ & $\begin{array}{c}d \mathrm{D}_{2} \mathbf{0} \\
\mathrm{gm} . / \mathrm{ml} .\end{array}$ & $\begin{array}{c}d \mathrm{D}_{2} \mathrm{O}-d \mathrm{H}_{2} \mathrm{O} \\
\mathrm{gm} . / \mathrm{ml} .\end{array}$ & $\frac{d_{\mathrm{D}_{3} \mathrm{O}}}{d \mathrm{H}_{2} \mathrm{O}}$ \\
\hline $\begin{array}{c}3 \cdot 8 \\
5 \\
10 \\
11 \cdot 2 \\
15 \\
20 \\
25 \\
30 \\
35 \\
40 \\
45 \\
50 \\
55 \\
60 \\
65 \\
70 \\
75 \\
80 \\
85 \\
90 \\
95 \\
100 \\
101 \cdot 4\end{array}$ & $\begin{array}{r}1 \cdot 00000 \\
0.99999 \\
9973 \\
9961 \\
9913 \\
9823 \\
9707 \\
9568 \\
9406 \\
9225 \\
9024 \\
8807 \\
8573 \\
8324 \\
8059 \\
7781 \\
7489 \\
7183 \\
6865 \\
6534 \\
6192 \\
5838 \\
5736\end{array}$ & $\begin{array}{r}1 \cdot 10538 \\
10555 \\
10595 \\
10596 \\
10583 \\
10530 \\
10440 \\
10319 \\
10169 \\
09992 \\
9790 \\
9565 \\
9319 \\
9054 \\
8771 \\
8471 \\
8154 \\
7821 \\
7472 \\
7109 \\
6732 \\
6342 \\
6229\end{array}$ & $\begin{array}{r}0 \cdot 10538 \\
556 \\
622 \\
635 \\
670 \\
707 \\
733 \\
751 \\
763 \\
767 \\
766 \\
758 \\
746 \\
730 \\
712 \\
690 \\
665 \\
638 \\
607 \\
575 \\
540 \\
504 \\
493\end{array}$ & $\begin{array}{r}1 \cdot \mathbf{1 0 5 3 8} \\
\mathbf{5 5 6} \\
\mathbf{6 2 5} \\
639 \\
678 \\
726 \\
764 \\
798 \\
827 \\
851 \\
871 \\
888 \\
902 \\
913 \\
924 \\
933 \\
940 \\
946 \\
950 \\
954 \\
957 \\
960 \\
960\end{array}$ \\
\hline
\end{tabular}

laboratory ${ }^{2}$ are slightly too high, and those of Wirtz too low, while Bridgman's approximate values? for $60^{\circ}$ and $80^{\circ}$, which represent the only known data above $50^{\circ}$ up to the present, are much too high.

Experimental details will appear elsewhere.

${ }^{1}$ Stokland, K., Ronaess, E., and Tronstad, L., Trans. Farad. Soc., 35, $312(1939)$

${ }^{2}$ Chang, T. L., and Chien, J. Y., J. Amer. Chem. Soc., 68, 1709 (1941).

${ }^{3}$ Wirtz, K., Naturwiss., 30, 330 (1942) : Physik. Z., 43, 465 (1942).

" "International Critical Tables", 3, 24 (1928). Stăhler, "Handbuch der Arbeitsmethoden in der anorganischen Chemie", $3 / 1,51$ (1913). ${ }^{5}$ Swift, E., Jr., J. Amer. Chem. Soc., 61, 198 (1939).

- Tronstad, L., and Brun, J., Trans. Farad. Soc., 34, 766 (1938).

${ }^{7}$ Bridgman, P. W., J. Chem. Phys., 3, 597 (1935).

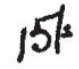

\section{MATHEMATICAL ASSOCIATION}

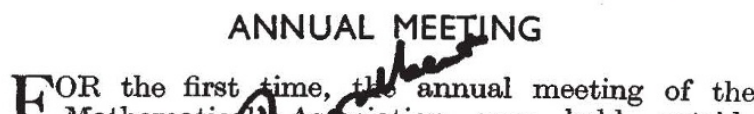

H OR the first fime, th annual meeting of the London; at and invitation of the Association's Midland Bra ch, and with the generous co-operation of the $\theta$ tiversity of Birmingham, which provided lecture theatres and hostel accommodation, the Assdciation met at Birmingham during April 20-23.

Duties abroad prevented the president, Sir Harold Spencer Jones, Astronomer Royal, from attending the meetings. In his absence, Mr. A. W. Siddons presided over the business meeting on April 21, at which Mr. A. Robson, until recently senior mathematical master at Marlborough College, was elected president for the forthcoming year. Sir Harold Spencer Jones will give his presidential address next year, Mr. Robson having agreed to give his address this year to fill the gap. Under the title, "How they Learnt, 1600-1850", Mr. Robson traced the development in content and treatment of the mathematical curriculum in English schools during this period, based on a study of text-books and school records, particularly those relating to Christ's Hospital. Mir. Robson's investigations show that the common view that mathematics was taught entirely as an academic subject, with little relation to practical applications, is not wholly correct. Prof. S. Brodetsky, formerly of the University of Leeds, then gave a lecture on nomography, showing how the solution of equations and the performance of various types of calculation can be carried out rapidly and with reasonable 
accuracy by means of the alignment of points on scale-carrying lines. For the remainder of April 21, a programme of excursions and entertainment was provided.

The morning of April 22 was occupied with two lectures: Dr. W. M. Hampton outlined the mathematical investigations which have been made into certain practical problems in glass-working, showing a very fair correspondence between theory and practice. Prof. R. Peierls, of the University of Birmingham, spoke on "Mathematics-Dead or Alive?", and emphasized a principle which has always been fundamental in the Association's policy, that mathematics cannot successfully be taught as a dead subject, but only as a living organism in contact with present-day developments, whether these be in the applications of mathematics to problems of importance in other sciences or in the extension of mathematical knowledge itself by current research.

Two valuable discussions filled the afternoon session. In opening the discussion on "A Realistic View of Main School Geometry", Mr. C. V. Durell proclaimed that geometry is a physical science, not a pattern of logical relations between mathematical abstractions ; but Mr. Robson, following Mr. Durell, maintained that a logical system of some kind must be developed in the later years of the school geometry course. In the following open discussion, there appeared to be some feeling among the younger teachers that the reaction against Euclid in the schools may be in danger of going too far. The other discussion, on "Alternatives to School Certificate Mathematics, with reference to Secondary Modern Schools", opened by Mrs. E. M. Williams (City of Leicester Training College) and Mr. R. C. Lyness, a Ministry of Education inspector, reflected the Association's close attention to the problem of mathematical teaching in the new Modern School, where there is a danger that content and method may be too closely.a copy of content and method in the Grammar School, instead of being firmly based and developed on the functional needs of the Modern School.

In the evening, Mr. J. A. Petch, secretary of the Joint Matriculation Board, spoke on ta subject of vital interest to teachers, "Statistical Treatment of Examination Niarks". Mr. Petch described the mathematical methods used in dealing with largescale external examinations in order to minimize variations, to standardize the markings of a panel of examiners who share the assessment of scripts in one subject, and to set up a standard of compacison between markings in different subjects. His audience welcomed his demonstration of the skill, care and patience devoted to the assessment of the merits of the School Certificate candidate.

On the morning of April 23, a first step was made on a programme which the Association hopes to follow up in later meetings, by getting speakers from outside Great Britain to deal with aspects of mathematical education in their countries. On this occasion, Mr. B. T. Gilroy, of New South Wales, and Mr. R. G. Keats, of South Australia, outlined the system of mathematical teaching in the secondary schools and universities of Australia. Dr. H. C. Christofferson, of Oxford, Ohio, described the ideals which inspire the teachers of mathematics in the high schools of the United States ; members of the Association supported his plea for a complete fusion of theory with practice, appreciated his illustrations of detail, and relished his fund of American anecdote.

\section{A NEW FOSSIL GYMNOSPERMOUS 'OVARY' RPl'}

7 HE discovery of a new type of many-seeded fruit bogy fro $n$ the Lower Carboniferous of Scotland is a iftiter of more than local palæobotanical interest. Thel publication by Prof. John Walton of the ful description of Calathospermum scoticum (Tran .. Roy. Soc. Edin., 61, 719; 1949), which has bef afraited since the preliminary account in $1940^{1}$, is herefore most welcome, although it is difficult to withhold a protest that any learned society, so long after the end of the War, should subject important scientific work to the treatment recorded in the superscription "MS. received May 10th, 1947. Read May 3rd, 1948. Issued separately Feb. 11th, 1949."

Calathospermum scoticum consists of isolated fruit bodies of large size (up to $24 \mathrm{~mm}$. $\times 45 \mathrm{~mm}$.), shaped like a tulip and each consisting of a cupule divided into six segments which surround either a central mass of stalks or an equivalent number of stalked ovules. Compared with other known many-seeded cupules (Gnetopsis and Calathiops), Calathospermum is the first to be discovered of Palæozoic age in which the mode of arrangement of the ovules inside the cupule can be studied, thereby contributing some very interesting comparative facts to place beside the better known but much more recent Caytonia. The stalks in Calathospermum are partly borne on the margins of the cupule segments but also on a quadri. partite central column to which some twenty-four of them may be attached. Each stalk has a central vascular strand which is continued into the integument of the ovule and out into its appendages. The latter consist of nine terete apical projections of considerable length which terminate the orthotropous ovules. In the form of these appendages and in other characters the ovules themselves resemble very closely those of Salpingostoma dasi described by Gordon in $1941^{2}$, although they are thought to be specifically distinct. Salpingostoma, interestingly enough, is itself the oldest structurally preserved seed which can be assigned with certainty to the Pteridosperms.

In attempting to interpret the presence of two states of the fruit bodies, those containing ovules on badly preserved (and therefore perhaps immature) stalks and those containing well-preserved stalks but no ovules, the suggestion is made that the latter are probably in the more advanced developmental state. It is thought that, as the seeds ripened, their stalks may have elongated and extruded them from the cupule, after which they became detached. From details observed in the histology of the cupule seg. ments it is thought that these may have opened out in a perianth-like manner during extrusion of the seeds, although in the water-logged condition pre. ceding fossilization they had again closed.

The fruit body appears to have been borne on the end of a stalk containing a single crescentic vascular strand. It is therefore concluded that they were foliar and not axial appendages.

For the non-specialist reader a valuable com. mentary on these facts will be found in the recently published Symposium on the Evolution and Classification of the Gymnosperms held in Chicago in December 1947. Prof. H. N. Andrews's paper ${ }^{3}$ in particular supplies a very valuable background in his survey of existing knowledge of Pteridosperms ir general, while Prof. B. Sahni ${ }^{4}$, by giving details 0 